\title{
A comprehensive introduction to Lacan's theories of psychosis
}

\section{Jonathan Douglas Redmond*}

Psychoanalytic Studies, Deakin University, Burwood, VIC, Australia

${ }^{*}$ Correspondence: jon_redo@yahoo.com
A book review on
The subject of psychosis: a Lacanian perspective

by Stijn Vanheule, Palgrave Macmillan, 2009, xxiv + 208 pages, 9780230276642
Vanheule's (2011) book The subject of psychosis: a Lacanian perspective provides a comprehensive introduction to Jacques Lacan's major theoretical contributions to psychosis. Lacan's theoretical engagement with psychosis constitutes a central platform for his ventures into psychoanalysis; from his doctoral thesis on paranoia in the 1930s through to his seminar on Joyce in the 1970s, the question concerning the psychoanalytic treatment of psychosis was at the forefront of his clinical work. In fact, Vanheule's central claim is that Lacan elaborated four distinct theories of psychosis over the course of his teaching.

Vanheule provides a chronological approach to his presentation of the four distinct theories of psychosis running through Lacan's oeuvre. They are "The age of imaginary identification” (1930s-1950), "The age of the signifier" (1950s), "The age of the object $a$ " (1960s), and "The age of the knot" (1970s). Moreover, this outline parallels the relative emphasis given to the registers of the imaginary, the symbolic, and the real (RSI) in Lacan's teaching. By doing this, he show how Lacan's continual engagement with the RSI, particularly the symbolic, and the real, is directly concerned with clinical problems specific to psychosis, a point evident in the final two chapters.

It is interesting to note that Vanheule spends a disproportionate amount of time on chapter two "The age of the signifier." While chapters one, three, and four are approximately the same length, chapter two is more than double in length to the others. Here, he spends considerable time devoted to Lacan's “classical theory of psychosis" the period most familiar to Anglophone readers. Although he does traverse familiar ground, his focus on Lacan's lesser-known psychiatric influences such as de Clérambault, the description of the centrality of language phenomena in psychosis, and, the clarity of the exposition, entails that these ideas are well worth revisiting. A considerable strength of this section is how Vanheule is able to provide a clear exposition of central tenants of Lacanian theory in a manner that is both comprehensive and segues into the theory of psychosis. For example, by examining key Lacanian ideas such as the subject of the unconscious, the signifying chain, and metaphor and metonymy he provides the basis for examining how a disturbance to language is central to psychosis. Lacan's thesis that a "psychotic structure" emerges from the foreclosure of a signifier, the Name-of-the-Father, is cogently discussed with reference to both language disturbances and the subject of the unconscious. Vanheule's explication of psychosis in terms of the difficulty a subject may have in producing meaning - i.e., signifiers - in a variety of situations is illuminating. Hence, the subsequent focus on clinical phenomena frequently encountered in psychosis - hallucinations and delusions - is clearly linked with how disturbances to the subject, at the level of the signifying chain, can result in the emergence of psychotic phenomena.

An interesting feature of his book is how Vanheule contends with the four distinct eras underpinning Lacan's engagement with psychosis. In his introduction, Vanheule states how "the attentive reader will observe that some of the ideas reviewed during my discussion of these four periods are complementary, while others are somewhat contradictory ... I attempted neither to resolve nor to conceal such contradictions. The more critical reader can decide how to proceed with them" (pp. 4-5). On the one hand, it is clear that Lacan's first theory of psychosis fell by the wayside after the 1950s. Vanheule claims that Lacan's early application of psychoanalytic theory to psychosis appeared ad hoc and, more significantly, focus on the analysis of resistances and ego defenses was soon abandoned in favor of the "structural" approach. Thus, Lacan's critique of ego psychology in 1950s could just have easily be applied to his own formulations, albeit decades earlier! It is worth noting that the second era coincides with Lacan's plea for a "return to Freud" where the distinction between the subject of the unconscious and the ego was expounded in detail using the categories of the symbolic and the imaginary. On the other, from the 1950s through to the 1970s, Lacan's claim that "psychotic structure" is linked to the foreclosure of the Name-ofthe-Father remained a consistent reference. For example, in chapter three "The age of the object $a$ "Vanheule claims that "as consequence of the foreclosure of the Name-of-the-Father, the object $a$ and jouissance have a particular status in psychosis" (2011, p. 126). A strength of this chapter is that Vanheule synthesizes ideas from a range of Lacan's texts to provide a cogent outline of how psychosis is linked to the drives, the object $a$ and problems in regulating jouissance. Moreover, his explication of the object $a$ shows the influence of Freud, Klein, and Winnicott on what Lacan refers to as his most "original contribution" to psychoanalysis. However, in the final era "The age of the knot" Lacan's focus on the possible compensatory mechanisms in psychosis became increasingly important and 
provided the means for moving beyond certain rigid conceptions of psychosis presented in the 1950s, such as the exclusive relation between neurosis and psychosis and the centrality of the Name-of-theFather in theorizing psychic structure. Moreover, I think Vanheule provides an important insight into Lacan's interest in topology and the manipulation of knots. For Lacan, knot theory is a formal logical language, orientated to three-dimensional space, and thus provides the possibility for showing the different ways of knotting and linking the RSI. In outlining this premise, Vanheule not only clarifies the use of topol- ogy in the later Lacan, but also, opens the space for informed discussion in this difficult area.

In summary, in presenting four different eras in Lacan's thinking on psychosis, Vanheule has outlined the historical context, the evolution, and the antinomies inherent in Lacan's thinking. Thus, Vanheule's aim of stimulating further research into Lacanian theories of psychosis has, I think, been achieved. Overall, I think that this is an important book: it contributes to contemporary Lacanian scholarship, it is relevant to clinicians working with psychosis and, it will be accessible to non-specialist readers.

\section{REFERENCE}

Vanheule, S. (2011). The Subject of Psychosis: A Lacanian Perspective. London: Palgrave Macmillan.

Received:27 March 2012; accepted: 16 April 2012; published online: 07 May 2012.

Citation: Redmond JD (2012) A comprehensive introduction to Lacan's theories of psychosis. Front. Psychology 3:133. doi: 10.3389/fpsyg.2012.00133

This article was submitted to Frontiers in Psychoanalysis and Neuropsychoanalysis, a specialty of Frontiers in Psychology.

Copyright (c) 2012 Redmond. This is an open-access article distributed under the terms of the Creative Commons Attribution Non Commercial License, which permits non-commercial use, distribution, and reproduction in other forums, provided the original authors and source are credited. 